\title{
US Public Diplomacy in the Modern Era: A Review of Battles to Bridges
}

Hatice Altun

SUNY Buffalo

\section{Review article of:}

R.S. Zaharna, Battles to Bridges: US Strategic Communication and Public Diplomacy after 9/11 (New York: Palgrave Macmillan, 2014, 256pp., USD 35.00, paper).

\section{Introduction}

In Battles to Bridges, R. S. Zaharna has put together detailed empirical evidence, carried out in line with a rich theoretical framework, to enable a thorough descriptive and analytical treatment of the subject of US public diplomacy for the Middle East. The subject is a timely one in light of the debates that have ensued in the US since the 9/11 attacks, and the book is a must-read for all who want to gain insights into the US's efforts to address and engage with diverse global publics in the postmodern era.

The past decade has been a playground for accelerated economic and cultural globalization. Although globalization is hardly a new concept, the processes involved in the current phase of globalization are novel in intensity, scale and scope. Sociolinguist and anthropologist Jan Blommaert argues that the world is no longer a global village, as metaphorized by Mcluhan over five decades ago, but "a tremendously complex web of villages, towns, neighborhoods, settlements connected by material and symbolic ties in often unpredictable ways." Communication, as an essential top aid of globalization, has revolutionized world affairs, and through this complex web, news is transmitted at light speed across the globe. This new phase of globalization has also challenged the powers of the world which previously dominated the transmission of knowledge and shaped the opinions throughout the world. As Simon Anholt, an independent policy advisor and the founder of the Good Country Index, noted in 2014 at a software conference, "there is only one superpower left on the planet and its name is global public opinion". Today, global civil society is the new actor determining the success or failure of policies. The US government, though it struggles diligently, has arguably not been able to keep pace with this shift in world affairs. Zaharna provides a guide to what the Bush administration did and did not do in light of the challenges posed by new globalization processes. Her criticisms leveled first in 2010 and now in a new, 2014 edition enriched by Nicholas Cull's foreword, seem to remain unaddressed under the Obama

Hatice Altun, PhD Candidate, Graduate School of Education, Learning and Instruction Department, SUNY Buffalo. Email: haticealtun@gmail.com.

J. Blommaert, The Sociolinguistics of Globalization (United Kingdom: Cambridge, 2011), 1. 
administration, which suffers from many of the same problems with respect to America's global standing in relation to the Islamic State or al-Qaeda. This second edition is timely therefore in addressing the overarching question: "What is wrong with US public diplomacy and how can it be fixed?"

This review essay begins with an overview of Zaharna's book in three sub-sections: the legacy of lessons taken from post-9/11 public diplomacy; the impact of changes in political and communication dynamics on US public diplomacy; and the public diplomacy theory building process. This is then followed by a reflection by the author on the relevance of the grand strategy and tactics offered by Zaharna on contemporary US public diplomacy.

\section{Overview of the Book}

Zaharna's Battles to Bridges is well-researched and embedded in theory, and it relates public diplomacy with culture and intercultural communication. The author's adept language allows her to step out of the scholarly Ivory Tower and communicate her work with larger audiences, including those who seek to grasp the field of public diplomacy from outside the walls of academia. Zaharna's book serves two aims. First, it is written for the students, scholars and practitioners of the emerging field of public diplomacy. To that end, she reviews the two critical periods of post-9/11 public diplomacy: from 2001 to 2004 and from 2004 to 2008 . The earlier period is particularly important because, she argues, it enables the reading public to reconstruct the rich details of the period with original documents likely to disappear rapidly from the Internet. The second purpose of the book is to lay the grounds for preliminary theory building in public diplomacy, which is a burgeoning field of study. Zaharna aims to provide students, researchers and diplomats with the necessary theoretical lenses to define effective public diplomacy. The book is divided into three main sections with three chapters in each. What follows is an overview of the three main sections.

\subsection{Legacy of the lessons of post-9/11 public diplomacy}

Chapter 1, America's Communication Problem, opens with the now-forgotten outpouring of support the US received right after the 9/11 attacks and then traces the political events that gave rise to the decline of this worldwide support. Zaharna first depicts the general atmosphere of the critical period (2001-2004) and provides compelling and comprehensive details of the political moves as follows. Most of the world, including all Middle East countries, from Jordan to Indonesia, all the Arab and Islamic world, Africa, Asia, Europe and Australia showed their verbal and symbolic support following the attacks, and more than 100 countries vowed to grant military, political, economic and legal cooperation to America in a true international war on terrorism, which started in Afghanistan on October 7, 2001 against al-Qaeda and Osama bin Laden. As America's diplomatic campaign for a full-fledged attack in Afghanistan became more aggressive and the rhetoric began to switch from "terrorism" to "radical Islam," concerns grew in the Islamic Arab world, and anti-American demonstrations from Pakistan to Indonesia started under the unifying banner of Islam. Reactions spread throughout the international community after the 2002 declaration of the expansion of war against terrorism to comprise the Arab Gulf region and with the growth of US public diplomacy rhetoric such as the "axis of evil", "you are either with us or with the terrorists," and wanting Osama bin Laden "dead or alive." Such moves strengthened stereotypes of America as being 
"hypocritical, arrogant, inattentive, unable to engage in cross-cultural dialogue," (16) and helped spark worldwide antiwar rallies from Tokyo to San Francisco. ${ }^{2}$ In 2003, as the US entered Iraq in disregard of the UN report stating a failure to find any weapons of mass destruction in Iraq, France, Germany and Russia all voiced strong opposition to the invasion, which then strengthened anti-American and/or anti-Bush sentiment worldwide.

Although many analysts focused on anti-Americanism at the time as it affected the US economically, politically, and militarily, Zaharna argues that the phenomenon was more complex than simply a need to improve the US's image in the world arena. According to her, America's communication problem led to a broader decline in its stature despite its communication efforts during the first critical phase of the post-9/11 period. Zaharna draws on the "mirror phenomenon" and on "perpetual gaps" to explain the communication breakdown that occurred between the international public and the American public. Mirror images of the two parties, the American image in the Islamic world and the image of Islam in America, were mutually reinforcing, i.e., in the countries or regions where America's image was low, the American public opinion of those regions was similarly low. As for Europe, Zaharna refers to perpetual gaps between American and international public opinion. Large perpetual gaps, i.e., to what extent the two parties share similar perceptions and opinions, exacerbated the communication breakdowns. Particularly, the negative perception of American power in Europe, and America's not taking her allies' opinions into consideration about the war in Iraq drastically worsened the relations in this critical period.

Although Zaharna draws on the "mirror phenomenon" and "perpetual gaps" to explain the reasons for the major communication breakdown at this time, her analysis could have benefitted from a historically grounded and politically engaged perspective on the matter rather than mainly basing her research on public opinion polls and surveys. We can consult Edward Said's Orientalism to inform ourselves on the complex, denigrating characterization of the East (including the Arab world) in the eyes of the colonial West, and Buruma and Margalit's Occidentalism: The West in the Eyes of Its Enemies, which highlights the antiWestern attitude in the larger East from Syria to Japan, where the writers diagnose the source of Occidentalism as the West itself. These refrains, orientalism and oxidentalism, can be deemed as the main contributors to the mirror images in both realms. The consequences are deep cultural misunderstandings of the Arab world and thwarted US political actions in the region, as Zaharna emphasizes.

In Chapter 2, Battle for Hearts and Minds, Zaharna surveys the intensive and expansive public diplomacy initiatives in the first phase post-9/11, 2001-2004. She highlights the central issue of most Americans having been "blissfully unaware of how they were perceived or what the consequences could be of anti-American sentiment" (29) prior to 9/11, and then examines in vivid detail the efforts subsequently made to improve America's image. From the comprehensive fact book "the Network of Terrorism," an electronic pamphlet entitled "Muslim Life in America," and an emphasis on the "Shared Values" theme, to "Hi" magazine, the pop music channel "Radio Sawa," and "Al-Hurra," a 24-hour Arabic language satellite TV station, Zaharna describes a number of "extremely innovative, ambitious and very expensive" public initiatives that never fulfilled the expectations of "winning hearts and minds" or of promoting American values, but served rather the opposite. Zaharna explicates 
how these attempts were considered as "condescending," "arrogant," "patronizing" and "slanted" because the audiences in the Arab world took them as an assault on their identity. At the same time, the brutal and insensitive actions of the troops in Iraq and particularly toward Abu Ghraib prisoners and to their culture and values were considered as reflecting Americans' true feelings towards the public in the region. She concludes that the US was not able to "cross the cultural and political hurdles" because they were not able to understand and value their audiences as being comprised of individuals.

In chapter 3, Search for Answers, Zaharna analyzes the failure of public diplomacy initiatives by examining the historically important special body of government and private reports that shaped US public diplomacy post-9/11. Unlike others, such as Kohut and Stokes, ${ }^{3}$ Zaharna argues that the US government realized that the communication breakdown did not stem from a lack of knowledge about American values and culture, and they began to seek answers for the inefficiency of US public diplomacy. Zaharna illustrates the process through a range of reports such as that by the Council on Foreign Relations in 2001, the Government Accountability Office's, and the 9/11 Commission's in 2004. She pinpoints that all these reports highlighted the origin of the problems in US diplomacy as dating back to the 1990s and to the end of the Cold War, and listed the major problems as "funding, structure, coordination, resources and strategy,"(58) the resulting offered solution being to develop a strategy resembling the Cold War model. Zaharna then describes the emphasis of individual diplomatic attempts made between 2004-2008 to improve America's stature in the global arena by stating many important names that worked as assets in this period, and concludes that however much effort was spent, US public diplomacy had neither the stability nor efficiency to succeed.

\subsection{Changing dynamics}

Chapters 4, 5, and 6 focus on the impact of changing political and communication dynamics in the international platform on US public diplomacy, and explore these dynamics under three sub-headings: connectivity, interactivity and cultural diversity. Chapter 4, which serves as an introduction chapter to the above mentioned issues, is twofold. First, it describes a historical context of US public diplomacy during times of war since the American Revolution and surfaces a detailed account of the recurring debates on traditional US public diplomacy patterns from the pre-Cold War and Cold War era. What follows is a helpful discussion of the key terminology associated with international relations (IR) by stating the nuances between phrases that are usually controversially used such as propaganda, public diplomacy, public relations and cultural diplomacy. In the second half of the chapter Zaharna portrays the postCold War era and the challenges encountered by US public diplomacy in a new globalization era revolutionized by digital communication. Zaharna then particularly explains the new power tools, people and dynamics of new public diplomacy in this era such as interactive social media, networking, the celebrities and nongovernmental organizations (NGO). She

In their book America Against the World, Kohut, the director of the Pew Research Center, and Stokes, NPR commentator, vaguely argue that the rest of the world hates Americans because they do not understand or they misunderstand Americans values of individualism, exceptionalism, and optimism in worldly issues. According to the Pew survey, polled in 50 countries with 91,000 people, it is concluded that the autonomous and mostly unilateral way of acting that America has demonstrated is considered by the world public to be mostly driven by America's over-nationalism and religiousness. The authors, however, argue that data collected in the US suggested that Americans do not feel that way and are not enthusiastic about their government's actions. 
criticizes US public diplomacy for trying to catch up with the post modern era by "simply employing new communication technology," rather than by developing new communication strategies to exercise soft power in the international arena such as "net activism, cyberadvocacy and e-advocacy based on efficient message exchange" to overcome the challenge posed by "the shift from message content to message exchange" (90).

Chapter 5 deals with the topic of soft power, i.e., "how to influence others through persuasion rather than force" and its two main assets: connectivity and interactivity, which have replaced the mass communication models that rely on information transmission (92). Zaharna draws attention to the key concepts and terminology in the field of public diplomacy and seeks to address to the differences between mass communication dynamics and network communication dynamics, i.e., "the first results in wielding soft power and the second in creating it" (111). She highlights the latter as the new age's source of creating soft power via agents like NGO and TAN (transnational advocacy networks), and illustrates the inner workings or networking of these agents to facilitate message exchange. Zaharna graphically exemplifies how an initiative based on network communication dynamics could possibly ease communication across cultural barriers via the example of Al-Hurra television. She then describes the three interrelated components of a network communication approach: a network structure that facilitates information exchange; network synergy as members combine power to multiply the effect of exchange; and network strategy that "uses information to co-create credibility, master narratives and identity" (107); and expounds on the reasons why US public diplomacy needs to adopt this approach. She argues that the reason for the failure of US public diplomacy is the dominant use of a mass communication approach which is inherently a message transmission strategy focusing on message content and dissemination of information used in the Cold War era.

In chapter 6, Zaharna explores culture and identity as important components of the new global era and deals with US public diplomacy with regard to its own cultural features. She discusses the underlying assumptions and presumptions of how cultural diplomacy played an essential role as "the linchpin of public diplomacy" (4) during the Cold War era. In the post 9/11 era, it was deemed that promotion of US cultural values had proved to be an effective public diplomacy asset behind the iron curtain, and thus the same tool could again be used to penetrate into the Islamic world. However, such attempts to promote US culture were already taken as identity assaults by the Islamic world. Thus, she argues that such an aggressive Cold War strategy cannot be as effective as it was in that era due to new globalization in the postmodern era. Unlike the narrow view of culture as a tool for communication of public diplomacy, IR studies, she argues, should focus on culture as a notion that spreads across the globe and should aim to help US public diplomacy develop a multicultural approach which feeds on cultural diversity. In this vein, since "culture becomes the new frontier for defining identities and allegiances" (115), it should be recognized as an integral part of communication that permeates several areas of IR and politics rather than as a tool for public diplomacy. Zaharna draws attention to the inherent cultural divergences between the West and the East and defines the problem in several US public initiatives as "not a lack of information but the differing cultural perspectives used to interpret the information" (120, italics mine). She thus contends that although it is the most challenging task to develop a multicultural approach by skillfully blending multiple perspectives in IR, such an approach may help public diplomacy tremendously to develop a more cognizant perspective of the Islamic world and deal with culturally diverse publics. 


\subsection{Expanding the vision of strategic US public diplomacy}

This third and last section of the book deals with the process of developing US public diplomacy theory across the three essential steps: grand strategy, strategy and tactics. Chapter 7 draws mostly on two main approaches assessed in chapter 5: mass communication and network communication dynamics. Zaharna introduces two main frameworks to analyze the US public initiatives in the post-9/11 period at the strategic and tactical levels. Given the discussions about the definition and contents of public diplomacy, she outlines the dominant features of an information framework, which basically assumes communication breakdowns occur either because of a lack of information or from mis-information, and thus relies on the control of information to fix such communication problems. Zaharna gives as examples various US initiatives: international broadcasting, information campaigns, nation branding, and media relations from the perspective of an information framework, and points out that this framework in US public diplomacy attitudes has been pervasive particularly in relation to the Islamic world. The other framework that Zaharna reviews is a relational framework, which focuses on setting up and maintaining relationships to solve communication problems. It is emphasized that US public diplomacy refers to cultural and educational exchange programs such as Fulbright and Humphrey as relational initiatives. Zaharna convincingly argues that in order to be able to expand the vision of US public diplomacy, both frameworks should be embraced complementarily; however, implementation of these frameworks will not be enough to make sure that US public diplomacy is effective and counterproductive. Therefore, she underscores the essential need for having a grand strategy that matches the communication and politics dynamics of the international arena to guarantee the effectiveness of US public diplomacy.

In chapter 8, Zaharna argues that failure of the US public diplomacy efforts in the post-9/11 period stemmed from two crucial reasons. The first one is related to the lack of theoretical knowledge to differentiate between the grand strategy of public diplomacy and the tactics and strategies of individual public diplomacy efforts. Drawing on Carl Botan's guideline to distinguish among the three levels of grand strategy, strategy, and tactics in public communication, Zaharna analyzes the existing grand strategy of US diplomacy as very similar to intransigent and resistant grand strategy, i.e., autonomous, highly motivated to defeat all competitors, public and communication technicians are excluded from the policy decision makings, control is vital, and change is not welcome. However, the presence of this already existing grand strategy is not recognized in public diplomacy, which makes the assessment of its match with the dynamics of the world very difficult.

The other and more important reason is the mismatch between the already existing grand strategy and the underlying communication dynamics of the new global era in the international platform. Zaharna argues that when one judges the expressed US diplomacy policy, specifically its focus on the dialogue with international publics, one can consider that US public diplomacy should in fact have a cooperative or integrative grand strategy, in which the organization is considered to be interdependent with the environment, the public is viewed as a legitimate stakeholder in the decision-making process, and change is preferred. However, a close look at the underlying dynamics of US diplomacy reveals that it is more likely to adopt intransigent or resistant grand strategies, which were viable during the Cold War era mainly because they corresponded with the communication and political dynamics of the time - a time when information dominance helped to win the battle. 
In line with Botan, Zaharna does not prefer one grand strategy over another, but rather, argues that the effectiveness and counter-productiveness of a grand strategy does not rely on its internal logic but on the match between the world view of the organization and the dynamics of the external world. In this vein, US public diplomacy suffered from this mismatch during the post-9/11 period. Given that, Zaharna suggests a grand strategy that would capitalize on a network communication approach and on connective, relational strategies, which are in accordance with the underlying political and communication dynamics of the new global era. She suggest that building bridges as a grand strategy works best with culturally diverse populations because it incorporates the two frameworks, informational and relational, and thus gives a cooperative angle to US public diplomacy to claim power in today's world. Zaharna concludes that "those with the most extensive and strongest communication bridges will command power in the global communication era" (173).

In the Epilogue, Zaharna expresses her raised hopes for a change in public diplomacy under the new Obama government, which had by the time of writing completed its 100th day in the office, due to the new administration's apparent adoption of a grand strategy of building bridges as judged by the early acts such as signing an executive order to close Guantanamo Bay within a year ${ }^{4}$, withdrawing US troops from Iraq and the emphasis on dialogue and diplomacy at the highest level. She observes that Obama's individual stance had initially created enthusiasm and sympathy around the world but this would not be enough for the implementation of building bridges as a grand strategy rather than fighting information battles. Zaharna recommends studying public diplomacy as a multidimensional area of research in close connection with culture, ethics, and non-state actors. She concludes the book by stating the need for a paradigm shift in US public diplomacy and an expansion of vision in strategic communication and public diplomacy, and suggests that unless US public diplomacy changes to keep up with the era, "increasing the budget and intensifying communication efforts may only further alienate publics and magnify problems rather than ameliorate them" (5).

In conclusion, when considering the detailed and careful exploration of the conceptual and theoretical underpinnings of US public diplomacy in the post-9/11 period, the book is likely to become a key manuscript for those who are involved in public diplomacy and international relations studies. By virtue of the importance of the subjects addressed in the book, it should also serve a wider interest to all who are involved in the area through research, teaching, and as practitioner diplomats. For those less familiar with or sympathetic to the field, a warning about the terminology and jargon: be ready to closely follow the steps, stages and levels that Zaharna provides in order to properly grasp her framework. By placing the discussion of US public diplomacy in its historical context, Zaharna eases the readers' path to comprehend the tangled issues about ideological and theoretical perspectives. Attentive perusal of the chapters is mandatory to avoid coming away with the impression that Zaharna is emotionally attached to the topic and is bent on criticizing the Bush government. The book is very likely to accelerate the on-going debate about US public diplomacy while tackling with the war on

4 As of today, Guantánamo Bay is still open and after delivering an economic speech in March 18, 2015, in Cleveland, Ohio, President Obama commented that he was regretful for not closing the detention camp and said that "I think I would have closed Guantánamo on the first day," but it is stated that closing Guantánamo would require cooperation from Congress, where Republicans have shown little indication that they would be willing to lift current restrictions on the closing of the prison. Although Obama repeated his intention to shut down the facility several times, the president has only been able to reduce the population at Guantánamo to 122 prisoners. 
terrorism focused now on both ISIS and al-Qaeda, and may tell us about the extent to which we need to re-think the previous decade and theories in public diplomacy to illuminate the contemporary times, and as such is an addition to the discussion in the following section.

\section{Reflections on the Obama Administration}

Addressing the summit on countering violent extremism held on February 18, 2015, President Barack Obama said "We are not at war with Islam. We are at war with people who perverted Islam," " thus seeking to strike a balance between gaining the confidence of the Muslim world while accentuating the US policy to stay determined and aware of the ideologies of the Islamic State or al-Qaeda terrorists. Prior to the summit, Obama was already trying hard not to attribute Islamic fundamentalism to the creed itself, and at the same time, according to his aides, what he aimed at was not to play into the hands of the ideological stand embraced by the Islamic State or al-Qaeda. However, Obama's word choice, including "Countering Violent Extremism" or "brainwashing" rather than "Islamic extremism," to describe the acts of the Islamic State or al-Qaeda terrorists, has been the topic of harsh criticism, particularly in domestic politics. Rudi Giuliani, the former New York City mayor and one-time presidential contender, went on record saying, "I do not believe - and I know this is a horrible thing to say - but I do not believe that the President loves America," and added: "He doesn't love you. And he doesn't love me. He wasn't brought up the way you were brought up and I was brought up through love of this country". ${ }^{6}$ Obama's vague phrasing, the opponents, vehemently on the right, a few liberals and former security officials, say, reflects uncertainty and weakness against extremists who claim to fight in the name of Islam and threaten America and its interests around the world.

On the other hand, Obama's rhetoric and his cautious stance for distancing Islam from the terrorist groups with whom Islamic peoples and governments never identify was appreciated by the Muslim world overseas and many advocates for Muslims: "We support the Obama administration and the administration before them for not falling into the al-Qaeda-ISIS trap of saying this is a religious war," said Farhana Khera, executive director of Muslim Advocates, a US-based Islamic group. ${ }^{7}$

Peter D. Feaver, a political scientist at Duke University, deeply involved in helping shape President George W. Bush's language, argues that choosing what to say about the enemy during the long campaign against al-Qaeda was a challenge for Mr. Bush, and now Mr. Obama has the same problem with the Islamic State. ${ }^{8}$ Zaharna too states that this has been a major challenge for both presidents: that of "how to bridge the inconsistencies between US public diplomacy goals and US domestic sentiment toward foreign publics" (178). In that sense, US domestic public opinion serves as a gauge for measuring the US image by the foreign publics. This discrepancy that the US presidents are displaying - the US public's actual sentiments and efforts to promote the likeability of the US in the Islamic world - has always the potential to cripple the effectiveness of US public diplomacy. Professor Akbar

5 Jim Acosta and Kevin Liptak, "Obama Proclaims: "We Are Not at War with Islam," CNN, February 19, 2015, http://edition. cnn.com/2015/02/18/politics/obama-speech-extremism-terror-summit/.

6 Jeremy Diamond, "Rudy Giuliani: Obama Doesn't Love America," CNN, February 19, 2015, http://edition.cnn. com/2015/02/19/politics/rudy-giuliani-obama-america-love/.

Scott Shane, "Faulted for Avoiding 'Islamic' Labels to Describe Terrorism, White House Cites a Strategic Logic," The New York Times, February 18, 2015.

8 Shane, "Faulted for Avoiding 'Islamic' Labels". 
Ahmed, chair of Islamic Studies at American University, who has been called "the world's leading authority on contemporary Islam" by the BBC, said that he approves of the Obama administration's diligence in avoiding a counterproductive smear of all Muslims. Yet he also said the President at times seems to draw on an academic approach to an ingrained, highly politicized discussion: "He sounds like a distinguished professor in the ivory tower, and he may have to come down into the hurly-burly of politics". ${ }^{9}$

Bernard Lewis, in his book What Went Wrong?: The Clash between Islam and Modernity in the Middle East, contends that though it may be commonplace to consider unavoidable the conflictual resulting nature of different cultures confronting, it's only indicative of the recent breakdown in communication and exchange between them. The insidious deeds of the Islamophobes, conceivably, has penetrated pop culture. In one recent example, Bill Maher, an American comedian, well known for the HBO political talk show Real Time with Bill Maher, said that "Obviously the vast majority of Muslims would never do anything like this [referring to the Charlie Hebdo attacks], but they share bad ideas". In that program he invited in Salman Rushdie, and quoted Sam Harris, an American author, who, as a guest on an earlier program had stated "Islam is the motherlode of bad ideas". ${ }^{10}$ Such portrayals of Muslims feed antagonism in the American public and create a larger Islamophobia. In tandem with Zaharna, it can thus be argued that in order to bridge the gap between the Western and Islamic worlds, the required change should be two-pronged in line with a contrary thinking against both orientalism and occidentalism. While the US should take pains to improve its image in the Arab and Islamic world, the Arab and Islamic world should also go over with a fine comb its own understandings of and policies towards the US. For now, however, both parties seem to reflect the metanarrative of the "clash of civilizations" in various ways.

Zaharna cautions that US credibility can be undermined unless the inconsistencies between US public diplomacy and US foreign policy are reconciled, and sees these deviations as having been the main challenge of the Bush government and to-be-challenges of the Obama government. In the same vein, in his recent book, Thistle and the Drone: How America's War on Terror Became a Global War on Tribal Islam, Ahmed criticizes both governments and argues that although Presidents Bush's and Obama's styles and content are different, the results have been the same. Arguing that there is an actual war going on in the tribal areas of Pakistan and Afghanistan between the American drones and tribal Islamic civilization, he projects his sentiments towards both governments:

Bush's administration, I felt, was spectacularly wrong because it was imposing a prefabricated
ideological frame on different cultures and societies, an exercise that was predictably bound
to run into trouble. Obama's administration was spectacularly unsure, and I looked in vain
for a coherent frame. It gave the impression of lurching dangerously from one crisis to
another as events on the ground developed and it reacted to them. Neither approach helped
the United States and the Muslim world resolve the problems that plagued them after $9 / 11$.
Both administrations were driven by issues almost wholly on a political level, neglecting the
moral and social dimensions and their implications. ${ }^{11}$

Zaharna's invaluable exploratory study is still illuminative in both senses. Thanks to her work, the Bush-era US public diplomacy lessons will not be forgotten. Moreover, through

\footnotetext{
9 Shane, "Faulted for Avoiding 'Islamic' Labels".

10 "Real Time with Bill Maher: Je Suis Charlie," YouTube video, 15:20, televised by HBO on January 9, 2015, posted by "Real Time with Bill Maher," posted by January 9, 2015, https://www.youtube.com/watch?v=GvgdPAEu8vA.

11 Akbar Ahmed, Thistle and the Drone : How America's War on Terror Became a Global War on Tribal Islam (Washington, DC, USA: Brookings Institution Press, 2013), 301.
} 
her wisdom, it is very striking to see through the growing scale of challenges that face US public diplomacy even as we start nearing the end of the Obama years. Although the negative repercussions of US foreign policy are still visible in the international arena, there is reason for hope that the tides will not return to the particularly problematic post-9/11 period, as long as the profoundness of the relational approach within the immense network of villages is mastered skillfully by US public diplomats. Acknowledging that the Cold War era is over, US public diplomacy should develop new strategies taking today's network-based communication dynamics into consideration in order to put an end to Battles and move the country towards Bridges to establish a long lasting peace and understanding between the United States and the rest of the world.

\section{Bibliography}

Acosta, Jim, and Kevin Liptak. "Obama Proclaims: "We Are Not at War with Islam.” CNN, February 19, 2015. http://edition.cnn.com/2015/02/18/politics/obama-speech-extremism-terror-summit/.

Ahmed, Akbar. Thistle and the Drone : How America's War on Terror Became a Global War on Tribal Islam. Washington, DC, USA: Brookings Institution Press, 2013.

Anholt, Simon. "Soft Power: An Evolving Challenge." Paper presented at the Wilton Park Conference on Soft Power in Action, London, February, 3-5, 2014.

Blommaert, J. The Sociolinguistics of Globalization. United Kingdom: Cambridge, 2011.

Botan, Carl. "Grand Strategy, Strategy, and Tactics in Public Relations.”In Public Relations Theory II, edited by C. Botan and V. Hazelton, 223-47. Mahwah, NJ: Lawrence Earlbaum, 2006.

Buruma, I., and A. Margalit. Occidentalism: A Short History of Anti-Westernism. London: Atlantic Books, 2004.

Diamond, Jeremy. "Rudy Giuliani: Obama Doesn’t Love America." CNN, February 19, 2015. http://edition.cnn. com/2015/02/19/politics/rudy-giuliani-obama-america-love/.

Houck, Curtis. "CBS, NBC Barely Touch on Criticism of Obama Refusing to Use the Term Islamic Extremism." February 18, 2015. http://newsbusters.org/blogs/curtis-houck/2015/02/18/cbs-nbc-barely-touch-criticismobama-refusing-use-term-islamic.

Kohut, A., and B. Stokes. America against the World: How We Are Different and Why We Are Disliked. New York: St. Martin's Griffiny, 2007.

Lewis, Bernard. What Went Wrong?: The Clash between Islam and Modernity in the Middle East. New York: Perennial, 2003.

Rivera, Zayda. "Real Time with Bill Maher: Ben Affleck, Sam Harris and Bill Maher Debate Radical Islam." New York Daily News, October 5, 2014. http://www.nydailynews.com/entertainment/tv/ben-affleck-calls-bill-maherviews-islam-gross-racist-disgusting-article-1.1963961.

McLuhan, M. The Gutenberg Galaxy. Toronto: University of Toronto Press, 1962.

Said, Edward W. Orientalism. New York: Vintage Books, 1979.

Shane, Scott. "Faulted for Avoiding 'Islamic' Labels to Describe Terrorism, White House Cites a Strategic Logic." The New York Times, February 18, 2015.

Siddiqui, Sabrina. "Barack Obama Regrets Not Closing Guantánamo Bay When First Elected.” The Guardian, March 18, 2015.

Tau, Byron. “Obama: U.S., West at War with Extremists, Not Muslims.” The Washington Post, February, 18, 2015.

U.S. Department of State. Report of the Advisory Committee on Cultural Diplomacy. Cultural Diplomacy: The Linchpin of Public Diplomacy. September, 2005.

Zaharna, R.S. Battles to Bridges: US Strategic Communication and Public Diplomacy after 9/11. UK: Palgrave Macmillan, 2014. 